\title{
Identifying and Prioritizing the Barriers of Implementation of Knowledge Management in Industrial Units and Providing Solutions to Eliminate them (Case Study: ParsianFanavaran Group)
}

\author{
GhasemTaghizadeh $^{1}$, Neda Ghavidast ${ }^{* 2}$ \\ 1- Faculty Member .Department of MBA, University of Malek AshtarIndustrial, Tehran, Iran. \\ 2- Msc.MBA .Department of MBA , Faculty of Management and soft technologies, University of Malek Ashtar \\ Industrial , Tehran, Iran. Email: Neda.ghavidast@gmail.com
}

\begin{abstract}
One cannot ignore the importance of knowledge in today's complex and global environment. Organizations that know how to collect, distribute and manage information effectively become industry leaders. Organizations are increasingly facing global competition and more complex customers. To survive in the competitive world, they should have an innovation in reducing the costs and expanding the market and increasing the efficiency of their processes. The importance of knowledge management is revealed at this point. Knowledge management (KM) not only has been proposed for the cost effectiveness and management effectiveness in problem solving, decision making and innovation, and other elements are needed to maintain and develop competitive advantage, but also it has been proposed more for obtaining, classifying, maintaining, and disseminating, and listing the knowledge and expertise consisting of an organizational memory in unstructured manner in the organization. Today's increasingly complex and changing competitive environment demands organizations that can survive in this area and make an effort to implement KM in order to gain competitive advantage. As the probability of failure of KM projects is high, these organizations should be able to predict their conditions with predictable scientific methods and strategies and implement appropriate strategies for the implementation of the project to achieve success. Considering these conditions, the project of the implementation of knowledge management in their organizations is facing challenges and complexities, so that lack of identifying and eliminating these barriers before and during its implementation will lead to a failure of the KM project. Accordingly, despite the resources and time spent in the organization, it will be impossible to use the benefits of implementation of knowledge management project. In this study, the status of the studied organization was firstly investigated in terms of implementation of knowledge management. Then, the main barriers of implementation of knowledge management were identified through library resources, interviews and questionnaires. After that, the priority and importance of barriers were identified and the relationships among the data were analyzed. Having a proper and realistic view and perspective and considering the current status of the organization, some recommendations were presented to eliminate these barriers of order to increase the probability of success of the implementation of knowledge management project.
\end{abstract}

Keywords: Knowledge management, Defense industry organization, Implementation of knowledge management system, System dynamics

\section{1- Introduction}

Considering the 20-year outlook of Iran (Horizon Outlook 2023), one of the significant areas in the science and technology sector is the development and promotion of knowledge-based organizations. The Defense Industries Organization as one of the requirements to become a knowledge-based organization has paid special attention to the implementation of comprehensive knowledge management system at all its levels, especially at operational units. Hence, identifying the factors of success and barriers of implementation of knowledge management system and planning to enhance the strengths and eliminate and reduce the weaknesses are considered as important points for the organization. Making use of all benefits and advantages of KM in addition to needed cost and time and appropriate investment, requires the proper implementation of knowledge management system in the organization. Thus, identifying and eliminating the barriers of implementation of a knowledge management project with a proper method in the organization can lead to making use of the benefits of knowledge management, otherwise, it will lead tothe waste of resources (cost and time). Review of the studies conducted so far revealed that less research has been conducted to investigate these issues directly in the Defense Industries Organization or similar organizations (public, industrial, defense and mission-oriented 
organizations, and number of units, etc.). Thus, in order to avoid making non-rational and non-scientific decisions, it is necessary to conduct a local study in the organization by considering its specific conditions. Determining the general status of the studied organization in terms of implementation of a knowledge management system, identifying and prioritizing the main barriers of implementation of a knowledge management system in the Defense Industries Organization, evaluating the indicators with a dynamic approach, and providing suggestions to remove the barriers of implementation of knowledge management system could be the expected results of this research.

\section{2-Review of literature}

The knowledge has grown rapidly in recent years and its impact is quite tangible and undeniable even in our everyday life, so that in the twentieth century, with the advent of new communication technologies and the possibility of exchanging the large volume of knowledge every few years, the processing of large volume of information by computers has doubled. This change also has reduced its average life span. However, these rapid developments and growth have created a new attitude in business management to provide the conditions for much use of knowledge and its growing. However, it should be notated that knowledge management has existed since old days and before the advent of information technology, and human beings have tried to preserve their existing knowledge in the past and promote it. For example, it can be stated that the oldest form of knowledge management is the use of human memory to store knowledge, leading to dissertation of the initial message over time. With the invention of writing, human beings tried to preserve their knowledge on clay tablets and later on papyrus and paper, and later, they tried to establish libraries to maintain and enhance their knowledge.

With the development of the printing industry, a transformation was made in preservation and dissemination of knowledge at large scales. The next major development was the invention of computers in the twentieth century, which made possible the expansion of methods of organizing, storing, sharing and assessing knowledge at wider levels. The development of computer technology made it possible to store, process and retrieve much knowledge in the shortest time with minimal cost. In the present age, knowledge is considered as a valuable and strategic resource. It is viewed as an asset along with resources such as land and capital (considered more in past), and even more so important than them, especially in knowledge-based organizations. Accordingly, providing the products and services with the proper, economical and desirable quality to customer without the proper management of this valuable resource seems to be impossible. Thus, industry is no longer at the core, rather the knowledge is at the core of organizations.

In the area of implementation of knowledge management, we should treat with caution, because according to the study conducted by Roth, 40 to 60 percent of KM projects have failed in this regard. DaneshFard and Shahabinia (2010) have argued that the existing organizational culture prevents the implementation of knowledge management in the company.Pawlin and Mason`s research also showed that the main barrier for the implementation of knowledge management is organizational culture. March and Jones concluded in their research that in most organizations, the existing organizational culture does not support the knowledge management. Investigating different views and hypotheses, Vaezi and Moslemi (2009) have considered the factors of cultural factors and organizational structure as the most important factors affecting the implementation of knowledge management.Koppta and Daragan argued that the KM is a cultural issue rather than a technological and technical issue and the key element is gaining the trust of the people involved in KM. Fadaei, Hasanzadeh and Zarrati (2011) argued that knowledge management system will not be able to achieve the desired success when the knowledge is not managed well. Amin Bidokhti, MakvandHoseini and Ehsani (2011) have argued that the hierarchical culture and hierarchical structure do not create the necessary flexibility in the organization.Zyngier (2002) stated that there are many factors having a negative impact on the implementation of knowledge management in organizations that are known as barriers of knowledge management. They might be caused by internal or external barriers. Internal barriers are rooted in culture and organizational structure and external barriers are often outside of the organization`s control. The important question for management researchers is the factors of success or failure of the project in the employment of knowledge management in organizations. Various factors, such as organizational structure, person, and organizational culture, have been studied in various studies. However, the focus of most studies has been on key factors for the success of KM. Although there is vast literature on knowledge management, there are limited studies on the barriers of knowledge management, especially in Iranian organizations. In most of the domestic studies, knowledge management has been studied in general, and at the most, the barriers have been identified, but they have not been prioritized. Without using a systematic approach, only the barriers have been identified. In most of these studies, culture has been reported as the main factor of success.

Zahedi and Entezari (2007) viewed the culture as the most important barrier to the success of KM activities. HaghighatMonfared and Hushyar (2010) stated that organizational culture is a key factor for success and concluded that the poor status of indicators of cultural dimensions weakens the indicators of knowledge management in the statistical population. Daneshfard and Shahabinia (2010) stated that the studies have shown 
that existing organizational culture prevents the implementation of knowledge management in the company. According to Pawlin and Mason, the main barrier for the implementation of knowledge management is organizational culture. March and Jones concluded that in most organizations, the existing organizational culture does not support the management of knowledge.SeyedJawadin, Emami and Rastegar (2010) concluded that one of the main barriers of the implementation of knowledge management in organizations is organizational culture and changing culture is considered as one of the most important aspects of any knowledge management system. A research conducted by Honda reported that new knowledge would be useless unless the governing organizational culture is developed (Keshavarzi and Ramazani, 2010). Other studies have taken other components into account, such as organizational structure, person, and technology. Studying different views and hypotheses, Vaezi and Moslemi (2009) considered the culture and organizational structure factors as one of the most important factors affecting the implementation of knowledge management. Based on the analyses, the significant relationship between the components of knowledge management (generation and transfer of knowledge) and components of organizational culture (creativity and innovation, tendency to change, teamwork and paying attention to individuals), and organizational structure components (formalism, complexity, and concentration) has been confirmed. These factors are among the factors affecting the implementation of knowledge management in the company, which should be considered by senior managers. Based on the research conducted by SeyedJavadin, Emami and Rastghar (2010), one of the main barriers of the implementation of knowledge management in organizations is organizational culture, and change of culture is one of the most important aspects of each knowledge management system in the National Iranian Oil Refining and Distribution Company. They also stated that one of the barriers of implementation of knowledge management at the National Iranian Oil Refining and Distribution Company was the lack of negotiation spaces and learning chats, the culture of dialogue and exchange of opinions perceived by researchers during the research process.

Amin Bidokhti, MakvandHoseini and Ehsani (2011) stated that the hierarchical culture does not create the necessary flexibility in the organization. Thus, due to this factor, the employees of the organization are accustomed to existing organizational procedures and do not show any tendency to innovate and create new ideas. In addition, they are afraid of sharing their knowledge with others and transforming this knowledge into skills that can be effective in solving organizational problems. Hence, the conditions that hierarchical culture creates in the training environment cannot be a significant predictor in knowledge management.McDong considered the culture governing the organizations as one of the most important challenges in implementing knowledge management. In another study, Koppta and Daraghan reported that the KM is more a cultural issue rather than a technical and technological issue and gaining the trust of individuals in knowledge management is the most important element, and if the organizational culture does not support the trust, no technology would be able to bring the desired result (Keshavarzi and Ramazani, 2010).

Amohamadi emphasized that the main factors of success, which are less important than other factors in their research, include information technology, rewarding and motivating, and modeling the bests. Although information technologies such as document management systems, information search and retrieval engines and relational and object-oriented databases, groupware and workflow systems, and data mining tools and mechanisms facilitate the implementation of knowledge management, it should be noted that the technology is no single answer necessary for the implementation of knowledge management since technology, as Wang and Spinwall emphasized, is just one tool. Accordingly, paying less importance for this factor can be explained by experts from this perspective and finally leadership and support by senior management and organizational culture are considered as the main factors in success.Studies conducted in foreign countries, in addition to these factors, have addressed some delicate issue and it has been investigated in a systematic way. According to the study conducted by Roth, $40 \%$ to $60 \%$ of KM projects fail.

Karabag (2010) argued that up-to-date and well-known models such as Nonaka and Takeuchi Spiral Model, Probest Knowledge Management Structure Blocks, and the Munich Riemann Model did not respond to this high failure rate. Wong (2003) argued that organizations` attempts to become a knowledge-based organization would be successful if they have the cultural characteristics required to implement knowledge management in an organization. He also reported that the knowledge can be effectively created and shared in an organization if it is supported by the culture of the organization. He argued that organizational culture can be used as a powerful leverage to strengthen organizational behavior and a poor organizational culture prevents people to share their knowledge to maintain their own personal power and efficiency.For this reason, attitudes, beliefs and values of individuals play the central role in this regard. This barrier is so hard and resistant that Steve Alice calls it the real destroyer. The boundaries of information management and knowledge management can be distinguished. More information has a public aspect and it is gaining awareness on the address of a thing or an individual, while "knowledge" in understanding and organizing the subject, may be acquired through studying and experience. 
Wong (2009) stated that while organizations has paid much attention to knowledge management system, little research has been conducted to develop tools and methods for assessing and measuring the success of the knowledge management system, especially from the perspective of knowledge production. Nowadays, there are limited models and frameworks to assess the success of the KM system, especially those derived from empirical studies.The research conducted by D.SinghandR.Kant (2008) classified the barriers and stated that levels of barriers are important for understanding the successful implementation of knowledge management. Using an interpretative structural modeling, the lack of senior management commitment has been recognized as the most important barrier (due to its high driving power and lower dependence among all known barrier) of knowledge management.S.Zyngier (2002) stated that there are many factors that have a negative impact on the implementation of knowledge management in organizations, known as knowledge management barriers that may be caused due to internal or external barriers. Internal barriers are derived from culture and organizational structure and external barriers are often out of the organization`s control.There are some barriers of sharing knowledge and few numbers of researchers have investigated these barriers and characteristics of organizational structure. Knowledge management should be a two-way, three-way or four-way communication. In order to access new knowledge reservoirs, intergroup and intersectional communications is essential.Hansen (1999) referred to "one-way path" barrier of knowledge management in his research. Rynhardt (2008) stated that managers should facilitate more personal communication with employees to open up informal communication channels and identify the two main groups of knowledge management barriers:

Barriers related to individuals: They are related to culture, time, implicit knowledge, trust, value identification, language and preferential sharing.

Barriers related to organization: They are related to strategy development, rewarding, allocation of resources, senior management support, organizational structure, number of employees, organizational culture, one-way knowledge management, competition and leadership power.Karabag (2010) stated that based on the research conducted by Gerhard and Trener, the use of KM would fail due to the complexity of knowledge management and lack of a practical plan, especially if the success factors are not considered. Thus, the success or failure of using knowledge management depends on considering the determining factors and the success and failure factors must be considered simultaneously.Science literature can only present the publications that have investigated the success or failure factors and only a few authors such as Martini and Pellegrini and Piker have investigated both areas. In addition, one cannot find an inseparable approach in the factors of success and failure for the dimensions of technology, organization and person in the broad research literature. In general, only a few researchers, such as Alazami and Zaieri, Kant and Singh, Halavi and Piker, have ranked the factors and evaluated their desired determining factors. Hase and Sankaran and Davies (2006) stated that there are many reasons that why people may store, distort or manipulate information that most of them are related to the need for power.

Their studies revealed that KM processes may be manipulated to prevent the distribution of power. This dark side of the organization may be conscious or unconscious, which acts always in contrast to the interests of a group or part of the group. It is important for those involved in the KM project to know the intensity of dynamicity of this dark aspect and to know how it can interfere with their desired intentions. The reason for this behavior is to maintain and control the "power". Its effect on the other members of organizations would be helplessness, low spirit, little effort to develop skills and psychological stress, and a crisis occurs when a person who has destroyed the KM processes is not unexpectedly present at work for several weeks.BenMoussa (2009) has stated that companies have invested largely on knowledge management with the aim of building a knowledge capability and using it to achieve competitive advantage. The studies have also shown that not all knowledge management projects are successful. Some studies have reported that about 84 percent of KM projects fail. The high percentage of knowledge management failures can be explained in this way that the gap between users and management in the knowledge management goals and conditions leads to a failure.Abdullah and Marican (2008) pointed to an interesting barrier of sexual harassment behaviors considered as one of the human knowledge barriers. It can be unwanted and unpleasant and occur verbally, non-verbally, and physically. The knowledge management requires good and healthy relations between male and female employees. One of the common problems in communication is a false perception of sexual harassment between men and women.In Korea, 20 out of 30 construction companies had their knowledge management team in the organization. To ensure having access to knowledge and its reuse in an organization, individuals and project teams in construction companies need to share their knowledge.Fadaei, Hasanzadeh and Zarrati referred to an interesting point. They stated that lack of attention to the distinction between "the concept of knowledge management" and "knowledge management system", which is a very delicate issue, has caused confusion among the researchers in these studies. This is particularly evident in studies conducted on the success factors of a knowledge management system. Some researchers have referred to factors in the evaluation of the success factors of the knowledge management system that focus more on the conceptual and general success of KM and do not have a systematic look at this issue.The knowledge senior management is the executive manager responsible for 
maximizing the organizational values obtained through knowledge.He is also responsible for maximizing the return on investment in knowledge (human resource, processes, and intellectual capital), the exploitation and maintenance of intangible assets (skills and customer relationships), repeated successes, development of innovation, and avoidance of losing organizational knowledge as the main organizational capital. The skill of a senior manager of knowledge should include the management of human resource, communication, leadership, teamwork, and management change.Lack of attention to the role of the manager, called as knowledge senior management, is quite evident in the KS literature, while this person is part of a knowledge management system and in fact forms the core of it. Ignoring the human role and element in the KM literature shows that the prevailing view and belief is that in the process of knowledge management, technology can replace this human factor. Unless the role and importance of knowledge senior management has not been properly perceived, the knowledge management system will not be able to achieve the desired results and technology will never be able to reach human minds (Fadaei, Hasanzadeh and Zarrati, 2011).

Moghadam, RaminMehr and Heydari (2010) reported in their research that the main challenges facing organizations is the understanding of knowledge management and the way of its implementation. Generally, human resources and knowledge management are closely correlated and many KM projects have been failed so far due to ignoring the role of human factors. The major barriers of knowledge management can be classified into five main classes, including human factors, organizational factors, political factors, cultural factors and technical and technological factors and paying attention to each of these barriers is important and the elimination of these barriers requires investment. As stated, most studies have sought to determine and identify barriers of implementing knowledge management and they have less considered the interactions between these factors, except in a few studies conducted in foreign studies using methods such as interpretive structural modeling.The barriers of implementation of knowledge management suggest that success of knowledge management requires a firm commitment of organization to eliminate these barriers. Employees and managers should believe in knowledge management in the organization and its effectiveness so that they can take steps to eliminate these barriers.In addition to above-mentioned factors, other factors were also considered in this study according to the results of the researcher and the interviews. These factors are the most serious barriers of knowledge management that should not be ignored. Social conditions, and especially economic conditions, can have a significant impact on human resources as one of the components of knowledge management, and organizational considerations only by the management and one-way communication can also be among the serious barriers in this regard.

\section{3-Literature of KM in studied organization}

-Providing a Knowledge Management Project Charter

-Identifying custodians and reviewing the works done in the ParsianFanavaran Group

-Investigating the software and experiences of active advisors and preparation of description of services needed by company

-Holding bids and selecting an advisor

-Project implementation

3-1-Activities undertaken

-Formation of the steeringcommittee and the executive committee

-Receiving high level documents of the company

-Holdingknowledgemanagementmeetings from the perspective of knowledgemanagement

-Definition of knowledge and knowledge goal

Phase 1: Analyzing the current situation of company and development of a KM road map

-Selecting KM model for company

1- Investigating the most valid KM models and integrating the most important processes of them

2-Designingg the validation questionnaire of the selected model

3-Analyzing the validation questionnaire of the model and determining the final model

-Completing and analyzing the organization knowledge questionnaire from the perspective of knowledge management and identifying the strengths and weaknesses

-Development of road map and KM strategy

Knowledge management strategy

First strategy: Developing the knowledge-based organization 
Second strategy: Optimal utilization of knowledge and experience of the organization

Third Strategy: Identifying the needs and resources of knowledge in line with achieving the goals of the organization

Fourth strategy: Systematic implementation of knowledge management processes

\section{Knowledge mission of the company}

Relying on expert and knowledge forces, ParsianFanavaran Company is committed to provide creative and collective solutions for national and local projects related to knowledge and technologies and it will strive to take steps to add value and provide appropriate services to customers by facilitating and accelerating interaction with experts.

Second Phase: Development of culture and training

- Holding training courses

-Courses of training the concepts and definitions for representatives and managers

-Courses for knowledge writing workshop

-Courses of training the documenting experiences

- Course of training organizational change management and knowledge management structure

-Workshop for introducing the foundations of the COP expertise forums

For knowledge extraction teams

- Presenting knowledge management booklet (definitions, concepts, models)

- Holding over 100 sessions of culture development with project managers and experts

- Preparation of short sentences of famous people in the area of knowledge for the company calendar

Third Phase: Creating a structure and system

-Identifying knowledge management representatives

- Presenting and approving proposed organization management knowledge structure

-Designing forms and procedures appropriate to the approved structure

-Development of organizational knowledge management process

-Formulation of motivational regulations

Fourth Phase: Knowledge modeling

-Holding knowledge filed extraction sessions

-Extracting the knowledge tree of all project sections

-Providing fields to experts in each area and obtaining their opinions and finalizing the fields

-Determining the strategic level of knowledge fields

-Identifying knowledge experts in each of the extracted areas

Fifth phase: Designing and implementation of a comprehensive software system

- Identifying the requirements of the knowledge management system software

- Designing the identified modules

- Presenting the original version (demo) of system

- Training the team of system managers 
-Holding a training course on knowledge management software

-Obtaining the opinions to make changes needed

Sixth phase: Documenting the project experiences

- Extracting the project knowledge tree

-Extracting project knowledge

Technical experience

Project management knowledge

- Preparation of project knowledge document framework

- Hold several knowledge extraction sessions with project manager and project experts

- Collecting project-related documents for using them in the project experience document

Based on implementation of the above-mentioned six phases and the conducted studies, the intended unit investigated only three factors of organizational structure, technology and organizational culture and 5 factors needed to be improved.

\section{4-Methodology}

The proper method for descriptive studies is survey method. Therefore, the method used in this research was a survey method. The survey method refers to research procedures in which the researcher performs a survey on a sample or the entire population to describe attitudes, thoughts, behaviors or characteristics of the population.In this method, the researcher collects quantitative and numerical data using a questionnaire or interview. Using the statistical techniques, the researcher describes the answers and tests questions or hypotheses of the research (2003, Creswell). Therefore, in this research, the literature of the subject was reviewed using scientific resources and the theoretical foundations of the research and other findings of the domestic and foreign researchers. After collecting the findings and conducting the interview, an expert questionnaire was prepared and the views of the managers and experts of the organization were collected to obtain a proper outlook of the studied organization`s status. In the next step, the main elements and criteria as well as the relevant sub-criteria were identified and the relationships between them were evaluated. Then the data were analyzed using SPSS software. In the next step, using the Delphi method and Friedman method, the type of relationship between the criteria was determined.

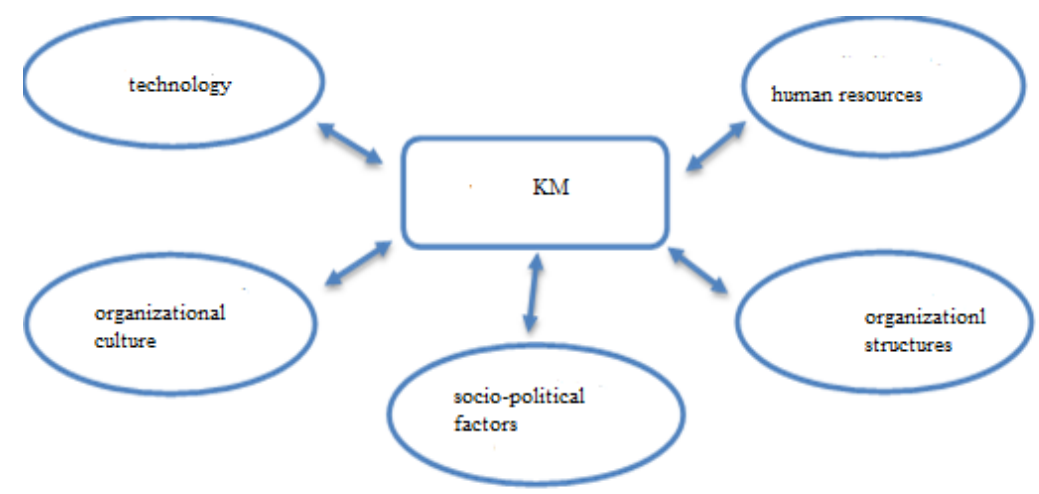

Figure 3.1. Proposed conceptual model

\section{4-1-Data collection method and tools}

The most common tool for collecting information in survey studies is questionnaire, so questionnaire was used in this study. Using computer, it was tried to ensure the accuracy in using the answers. The library resources and interviews were also considered. The sample research questionnaire has been presented in Appendix C. In this questionnaire, it was tried to identify the views and opinions of experts on the criteria and indicators in order to determine the final indicators. The information contained in this questionnaire was prepared by examining the questionnaires of other foreign and domestic studies on the knowledge management.In the designed questionnaire, questions were answered on a Likert scale in the form of I strongly agree, agree, no idea, disagree, and strongly disagree. Accordingly, qualitative and nonparametric information was interpreted 
quantitatively and numerically. The Likert scale was used to determine the importance of each of the variables. It should be noted that in this section of the research, 23 questionnaires were distributed among the experts.In this questionnaire, the main factors were categorized in five groups of organizational culture, organizational structure, human resources, technology, and social-social factors.

\section{4-2- Population}

The statistical population is a set of units that are common in one or more specific characteristics or attributes, and the aim of the research is to obtain information about them (VatanDoust and Sharafi, 2007).The statistical population of this study included 34 managers and experts of the ParsianFanavaran Group of Defense Industries Organization, which most of them had higher levels of education. By interviewing and questioning all 34 people through an expert questionnaire, the status of the organization in terms of research subject was determined.

\section{4-3-Data analysis method}

Statistical methods are used mainly for describing and analyzing data. In most organizational studies, the researcher is interested in gaining knowledge on the frequency of the occurrences of phenomena, mean or average of a set of variables, as well as the degree of variability within a group (for example, central tendency and the distribution of independent and dependent variables). These subjects are known as descriptive statistics (DanaeiFard et al, 2009). In this research, the classical method of descriptive studies (frequency, mean, variance, etc.) has been used.Accordingly, by identifying the influential factors (directly or indirectly) and after collecting the results and extracting the framework of barriers of implementation of knowledge management, criteria and sub-criteria were examined. Moreover, by analyzing the organization, the current status of the organization was determined. Using the Friedman test, the importance of the factors was determined and it was possible to determine the dependency of the factors to each other using the correlation test.

\section{4-3- Testing normal distribution of variables}

In this section, the research questions were tested. Before testing the questions, the Kolmogorov and Smirnov tests were used to test the normality of the data:

When testing the normality of the data, it is assumed thatregarding thenull hypothesis, the distribution of the data is normal at a $5 \%$ error level. Therefore, if the test statistic be greater than 0.05 , there would be no reason to reject the null hypothesis that the data is normal. In other words, the distribution of data will be normal. The hypotheses have been presented as follows:

$\mathrm{H}$ : The distribution of data for each of the variables is normal.

$\mathrm{H1}$ : The distribution of data for each of the variables is not normal.

Table 4.1. Testing the normality of research variables

\begin{tabular}{|c|c|c|c|c|c|c|}
\hline Description & $\begin{array}{c}\text { Cultural } \\
\text { factors }\end{array}$ & $\begin{array}{c}\text { Organizational } \\
\text { factors }\end{array}$ & Technology & $\begin{array}{c}\text { Human } \\
\text { factors }\end{array}$ & $\begin{array}{c}\text { Socio- } \\
\text { political } \\
\text { factors }\end{array}$ & $\begin{array}{c}\text { Implementation of } \\
\text { knowledge } \\
\text { management }\end{array}$ \\
\hline $\begin{array}{c}\text { Number of } \\
\text { samples } \\
\text { mean }\end{array}$ & 34.00 & 34.00 & 34.00 & 34.00 & 34.00 & 34.00 \\
\hline SD & 2.98 & 2.91 & 2.40 & 2.77 & 2.74 & 3.01 \\
\hline Positive values & 0.90 & 0.96 & 0.93 & 0.94 & 0.72 & 0.80 \\
\hline Negative values & $0.13-$ & 0.10 & 0.21 & 0.14 & 0.17 & 0.17 \\
\hline Kolmogorov- & 0.82 & 0.60 & $0.12-$ & $0.11-$ & $0.11-$ & $0.08-$ \\
\hline SmirnovZ & 0.52 & 0.87 & 1.23 & 0.78 & 1.01 & 0.96 \\
\hline Sig .Asymp & 0.96 & 0.10 & 0.57 & 0.26 & 0.31 \\
\hline Test result & normal & normal & normal & normal & normal & normal \\
\hline
\end{tabular}


According to Table 5-1, as the significance value of all variables was higher than 0.05 , it can be concluded that all the variables of the research were normal. Parametric tests such as correlation coefficient and regression can be used to test the research hypotheses.

\subsection{Descriptive statistics of the research questions}

In this section, descriptive statistics of research questions have been discussed:

\begin{tabular}{|c|c|c|c|c|c|}
\hline component & $\begin{array}{l}\text { Description } \\
\text { of questions }\end{array}$ & $\mathrm{n}$ & mean & SD & Mean deviation \\
\hline \multirow{5}{*}{$\begin{array}{l}\text { Implementation } \\
\text { of knowledge } \\
\text { management }\end{array}$} & Q30 & 34.00 & 3.06 & 0.95 & 0.16 \\
\hline & Q29 & 34.00 & 3.15 & 1.10 & 0.19 \\
\hline & Q28 & 34.00 & 2.94 & 1.04 & 0.18 \\
\hline & Q27 & 34.00 & 3.03 & 0.90 & 0.16 \\
\hline & Q26 & 34.00 & 2.85 & 1.13 & 0.19 \\
\hline \multirow{5}{*}{$\begin{array}{l}\text { Socio-political } \\
\text { factors }\end{array}$} & Q25 & 34.00 & 3.15 & 0.99 & 0.17 \\
\hline & Q24 & 34.00 & 2.44 & 1.02 & 0.18 \\
\hline & Q23 & 34.00 & 2.50 & 0.90 & 0.15 \\
\hline & Q22 & 34.00 & 2.56 & 1.13 & 0.19 \\
\hline & Q21 & 34.00 & 3.06 & 0.89 & 0.15 \\
\hline \multirow{5}{*}{ Human factors } & Q20 & 34.00 & 3.44 & 1.13 & 0.19 \\
\hline & Q19 & 34.00 & 3.06 & 1.10 & 0.19 \\
\hline & Q18 & 34.00 & 2.62 & 1.23 & 0.21 \\
\hline & Q17 & 34.00 & 2.56 & 0.82 & 0.14 \\
\hline & Q16 & 34.00 & 2.18 & 1.29 & 0.22 \\
\hline \multirow{5}{*}{ Technology } & Q15 & 34.00 & 1.88 & 1.01 & 0.17 \\
\hline & Q14 & 34.00 & 2.71 & 1.47 & 0.25 \\
\hline & Q13 & 34.00 & 2.50 & 0.99 & 0.17 \\
\hline & Q12 & 34.00 & 2.38 & 1.04 & 0.18 \\
\hline & Q11 & 34.00 & 2.53 & 1.35 & 0.23 \\
\hline \multirow{5}{*}{$\begin{array}{l}\text { Organizational } \\
\text { structure }\end{array}$} & Q10 & 34.00 & 2.88 & 1.07 & 0.18 \\
\hline & Q9 & 34.00 & 2.71 & 1.12 & 0.19 \\
\hline & Q8 & 34.00 & 3.09 & 1.19 & 0.20 \\
\hline & Q7 & 34.00 & 2.88 & 1.25 & 0.21 \\
\hline & Q6 & 34.00 & 2.97 & 1.27 & 0.22 \\
\hline \multirow{5}{*}{$\begin{array}{l}\text { Organizational } \\
\text { culture }\end{array}$} & Q5 & 34.00 & 3.32 & 1.07 & 0.18 \\
\hline & Q4 & 34.00 & 3.00 & 1.23 & 0.21 \\
\hline & Q3 & 34.00 & 3.24 & 1.21 & 0.21 \\
\hline & Q2 & 34.00 & 2.74 & 1.19 & 0.20 \\
\hline & Q1 & 34.00 & 2.62 & 0.89 & 0.15 \\
\hline
\end{tabular}


As shown in the table above, the highest mean was related to Q20 of the human factor and the lowest mean was related to the Q15 of the technology factors.

\section{4-5- Correlation coefficient of independent research variables:}

After collecting the experts' views and opinions using the correlation test method, the consistency rate of the aggregated answers was calculated, and the consistency rate of the pairwise comparisons wasmeasured. All of them were calculated less than acceptable level (0.1). The relationships in Table 4-2 have been calculated in pair using Pearson correlation coefficient:

Table 4.2. Correlation coefficient of independent research variables

\begin{tabular}{|c|c|c|c|c|c|}
\hline description & $\begin{array}{c}\text { Organizational } \\
\text { culture }\end{array}$ & Organizational structure & Technology & Human factors & Political factors \\
\hline $\begin{array}{c}\text { Organizational } \\
\text { culture }\end{array}$ & 1.00 & 0.80 & 0.68 & 0.52 & 0.57 \\
\hline $\begin{array}{c}\text { Organizational } \\
\text { structure }\end{array}$ & 0.80 & 1.00 & 0.70 & 0.74 & 0.71 \\
\hline Technology & 0.68 & 0.70 & 1.00 & 0.77 & 0.71 \\
\hline Human factors & 0.52 & 0.74 & 0.77 & 0.88 \\
\hline Political factors & 0.57 & 0.71 & 0.71 & 0.88 & 1.00 \\
\hline
\end{tabular}

As seen in the table above, there was a direct relationship between organizational culture and organizational structure and the value of this relationship was 0.8 . The value of the relationship between culture and technology was equal to 0.68 . Other information about the relationship between the independent variables has been presented in table above.

\section{5-Results of testing the hypotheses}

In this section, by presenting the research hypotheses and using the regression and Pearson correlation coefficient, the research hypotheses were tested and the results were analyzed.

1-Organizational culture has a positive impact on the success of implementation of a knowledge management system in an industrial organization.

2-Organizational structure has a positive impact on the success of implementation of a knowledge management system in an industrial organization.

3-Technology has a positive impact on the success of implementation of a knowledge management system in an industrial organization.

4-Human factors have a positive impact on the success of implementation of a knowledge management system in an industrial organization.

5-Socio-political factors have a positive impact on the success of implementation of a knowledge management system in an industrial organization.

First hypothesis of the research:

Organizational culture has a positive impact on the success of implementation of a knowledge management system in an industrial organization. 
Table 5.1. Summary of the first hypothesis of the model

\begin{tabular}{|c|c|c|c|c|}
\hline \multicolumn{5}{|c|}{ Summary of model } \\
\hline description & $\begin{array}{c}\text { Correlation } \\
\text { coefficient }\end{array}$ & $\begin{array}{c}\text { Coefficient } \\
\text { of } \\
\text { determination }\end{array}$ & $\begin{array}{c}\text { Adjusted } \\
\text { coefficient of } \\
\text { determination }\end{array}$ & $\begin{array}{c}\text { Deviation from } \\
\text { estimate }\end{array}$ \\
\hline $\begin{array}{c}\text { organizational culture and } \\
\text { implementation of a knowledge } \\
\text { management system }\end{array}$ & 0.537 & .288 & 0.266 & 0.68 \\
\hline
\end{tabular}

Table 5.2. Testing the first hypothesis

\begin{tabular}{|c|c|c|c|c|c|}
\hline \multicolumn{6}{|c|}{ Coefficients } \\
\hline & \multicolumn{2}{|c|}{$\begin{array}{l}\text { Non-standardized } \\
\text { coefficients }\end{array}$} & \multicolumn{2}{|c|}{ standardized coefficients } & \multirow[t]{2}{*}{ significance } \\
\hline $\begin{array}{l}\text { organizational culture and } \\
\text { implementation of a knowledge }\end{array}$ & $\begin{array}{c}\text { Beta } \\
\text { coefficient }\end{array}$ & SD & $\begin{array}{c}\text { Beta } \\
\text { coefficient }\end{array}$ & $\mathrm{T}$ value & \\
\hline management system & 0.48 & 0.13 & 0.54 & 3.60 & 0.00 \\
\hline
\end{tabular}

Based on the Table 5.1, the correlation coefficient between the variables of organizational culture and the success of implementation of knowledge managementwas 0.537 , indicating that there was a direct relationship between these two variables with a value of 0.537 . The adjusted coefficient of determination of organizational culture was 0.266 . It means that organizational culture had a $26 \%$ impact on the success of implementation of the knowledge management system. Based on Table 5-2, the significance of this hypothesis was equal to 0.000 . As this value was less than 0.05 , it can be concluded that there was a significant relationship between organizational culture and the success of implementation of knowledge management system in the statistical sample of the research and this relationship was direct. As organizational culture strengthened the knowledge management, the odds of success in the implementation of a knowledge management system in an organization became higher.

The second hypothesis of the research:

Organizational structure has a positive impact on the success of implementation of a knowledge management system in an industrial organization.

Table 5.3. Summary of the second hypothesis of the model

\begin{tabular}{|c|c|c|c|c|}
\hline \multicolumn{1}{|c|}{ Summary of model } \\
\hline description & $\begin{array}{c}\text { Correlation } \\
\text { coefficient }\end{array}$ & $\begin{array}{c}\text { Coefficient } \\
\text { of } \\
\text { determination }\end{array}$ & $\begin{array}{c}\text { Adjusted } \\
\text { coefficient of } \\
\text { determination }\end{array}$ & $\begin{array}{c}\text { Deviation from } \\
\text { estimate }\end{array}$ \\
\hline $\begin{array}{c}\text { Organizational structure`s } \\
\text { impact on the implementation } \\
\text { of a knowledge management } \\
\text { system }\end{array}$ & 0.59 & 0.34 & 0.32 & 0.66 \\
\hline
\end{tabular}

Table 5.4. Testing the second hypothesis

\begin{tabular}{|c|c|c|c|c|c|}
\hline \multicolumn{6}{|c|}{ Coefficients } \\
\hline & \multicolumn{2}{|c|}{$\begin{array}{l}\text { Non-standardized } \\
\text { coefficients }\end{array}$} & \multicolumn{2}{|c|}{ standardized coefficients } & \multirow[t]{2}{*}{ significance } \\
\hline \multirow{2}{*}{$\begin{array}{c}\text { Organizational structure`s } \\
\text { impact on the implementation } \\
\text { of a knowledge management } \\
\text { system }\end{array}$} & $\begin{array}{c}\text { Beta } \\
\text { coefficient }\end{array}$ & SD & $\begin{array}{c}\text { Beta } \\
\text { coefficient }\end{array}$ & $\mathrm{T}$ value & \\
\hline & 0.49 & 0.12 & 0.59 & 4.09 & 0.00 \\
\hline
\end{tabular}


Based on the Table 5.3, the correlation coefficient between the variables of organizational structure and the success of implementation of knowledge managementwas 0.59 , indicating that there was a direct relationship between these two variables with a value of 0.59 . The adjusted coefficient of determination of organizational structure was 0.32 . It means that organizational structure had a $32 \%$ impact on the success of implementation of the knowledge management system. Based on Table 5-4, the significance of this hypothesis was equal to 0.000 . As this value was less than 0.05 , it can be concluded that there was a significant relationship between organizational structure and the success of implementation of knowledge management system in the statistical sample of the research and this relationship was direct. It means that as organizational structure strengthened the knowledge management, the odds of success in implementation of a knowledge management system in an organization became higher.

The third hypothesis of the research:

Technology has a positive impact on the success of implementation of a knowledge management system in an industrial organization.

Table 5.5. Summary of the third hypothesis of the model

\begin{tabular}{|c|c|c|c|c|}
\hline \multicolumn{4}{|c}{ Summary of model } \\
\hline description & $\begin{array}{c}\text { Correlation } \\
\text { coefficient }\end{array}$ & $\begin{array}{c}\text { Coefficient } \\
\text { of } \\
\text { determination }\end{array}$ & $\begin{array}{c}\text { Adjusted } \\
\text { coefficient of } \\
\text { determination }\end{array}$ & $\begin{array}{c}\text { Deviation from } \\
\text { estimate }\end{array}$ \\
\hline $\begin{array}{c}\text { Technology impact on } \\
\text { implementation of a } \\
\text { knowledge management } \\
\text { system }\end{array}$ & .486 & 0.24 & 0.21 & 0.71 \\
\hline
\end{tabular}

Table 5.6. Testing the third hypothesis

\begin{tabular}{|c|c|c|c|c|c|}
\hline \multicolumn{5}{|c|}{ coefficients } \\
\hline description & \multicolumn{2}{|c|}{$\begin{array}{c}\text { Non-standardized } \\
\text { coefficients }\end{array}$} & standardized coefficients & significance \\
\hline $\begin{array}{c}\text { Technology impact on } \\
\text { implementation of a } \\
\text { knowledge management } \\
\text { system }\end{array}$ & $\begin{array}{c}\text { Beta } \\
\text { coefficient }\end{array}$ & SD & $\begin{array}{c}\text { Beta } \\
\text { coefficient }\end{array}$ & T value \\
\hline
\end{tabular}

Based on the Table 5.5, the correlation coefficient between the variables of technology and the success of implementation of knowledge managementwas 0.486, indicating that there was a direct relationship between these two variables with a value 0.486 . The adjusted coefficient of determination of technology was 0.21 . It means that technology had a $21 \%$ impact on the success of the implementation of the knowledge management system. Based on Table 5-6, the significance of this hypothesis was equal to 0.000 . As this value was less than 0.05 , it can be concluded that there was a significant relationship between technology and the success of the implementation of knowledge management system in the statistical sample of the research and this relationship was direct. It means that as the technology for KM was provided more, the odds of success in implementation of a knowledge management system in an organization became higher.

The fourth hypothesis of the research:

Human resources have a positive impact on the success of implementation of a knowledge management system in an industrial organization. 
Table 5.7. Summary of the fourth hypothesis of the model

\begin{tabular}{|c|c|c|c|c|}
\hline \multicolumn{4}{|c}{ Summary of model } \\
\hline description & $\begin{array}{c}\text { Correlation } \\
\text { coefficient }\end{array}$ & $\begin{array}{c}\text { Coefficient } \\
\text { of } \\
\text { determination }\end{array}$ & $\begin{array}{c}\text { Adjusted } \\
\text { coefficient of } \\
\text { determination }\end{array}$ & $\begin{array}{c}\text { Deviation from } \\
\text { estimate }\end{array}$ \\
\hline $\begin{array}{c}\text { Human resources impact } \\
\text { on the success of } \\
\text { implementation of a } \\
\text { knowledge management }\end{array}$ & 0.77 & 0.59 & 0.58 & 0.52 \\
\hline \begin{tabular}{c} 
system \\
\hline
\end{tabular} & & & \\
\hline
\end{tabular}

Table 5.8. Testing the fourth hypothesis

\begin{tabular}{|c|c|c|c|c|c|}
\hline \multicolumn{6}{|c|}{ Coefficients } \\
\hline Description & \multicolumn{2}{|c|}{$\begin{array}{l}\text { Non-standardized } \\
\text { coefficients }\end{array}$} & \multicolumn{2}{|c|}{$\begin{array}{c}\text { standardized } \\
\text { coefficients }\end{array}$} & \multirow[t]{2}{*}{ significance } \\
\hline $\begin{array}{c}\text { Human resources impact } \\
\text { on the success of }\end{array}$ & $\begin{array}{c}\text { Beta } \\
\text { coefficient }\end{array}$ & SD & $\begin{array}{c}\text { Beta } \\
\text { coefficient }\end{array}$ & $\mathrm{T}$ value & \\
\hline $\begin{array}{l}\text { implementation of a } \\
\text { knowledge management } \\
\text { system }\end{array}$ & 0.85 & 0.13 & 0.77 & 6.76 & 0.00 \\
\hline
\end{tabular}

Based on the Table 5.7, the correlation coefficient between the variables of human resources and the success of implementation of knowledge managementwas 0.77 , indicating that there was a direct relationship between these two variables with a value 0.77 . The adjusted coefficient of determination of human resources was 0.581 . It means that human resources had a $58 \%$ impact on the success of implementation of the knowledge management system.Based on Table 5.8, the significance of this hypothesis was equal to 0.000 . As this value was less than 0.05 , it can be concluded that there was a significant relationship between human resources and the success of the implementation of knowledge management system in the statistical sample of the research and this relationship was direct. It means that as human resources had more willingness for the implementation of knowledge management, the odds of success in the implementation of a knowledge management system in an organization became higher.

The fifth hypothesis of the research:

Socio-political factors have a positive impact on the success of implementation of a knowledge management system in an industrial organization.

Table 5.9. Summary of the fifth hypothesis of the model

\begin{tabular}{|c|c|c|c|c|}
\hline \multicolumn{5}{|c|}{ Summary of model } \\
\hline description & $\begin{array}{c}\text { Correlation } \\
\text { coefficient }\end{array}$ & $\begin{array}{c}\text { Coefficient } \\
\text { of } \\
\text { determination }\end{array}$ & $\begin{array}{c}\text { Adjusted } \\
\text { coefficient of } \\
\text { determination }\end{array}$ & $\begin{array}{c}\text { Deviation from } \\
\text { estimate }\end{array}$ \\
\hline $\begin{array}{c}\text { Socio-political factors impact on } \\
\text { implementation of a knowledge } \\
\text { management system }\end{array}$ & .611 & 0.37 & 0.35 & 0.64 \\
\hline
\end{tabular}

Table 5.10. Testing the fifth hypothesis

\begin{tabular}{|c|c|c|c|c|c|}
\hline \multicolumn{6}{|c|}{ Coefficients } \\
\hline description & \multicolumn{2}{|c|}{$\begin{array}{l}\text { Non-standardized } \\
\text { coefficients }\end{array}$} & \multicolumn{2}{|c|}{$\begin{array}{l}\text { standardized } \\
\text { coefficients }\end{array}$} & \multirow[t]{2}{*}{ e } \\
\hline \multirow{2}{*}{$\begin{array}{l}\text { Socio-political factors impact on } \\
\text { implementation of a knowledge } \\
\text { management system }\end{array}$} & $\begin{array}{c}\text { Beta } \\
\text { coefficient }\end{array}$ & SD & $\begin{array}{c}\text { Beta } \\
\text { coefficient }\end{array}$ & $\mathrm{T}$ value & \\
\hline & 0.52 & 0.12 & 0.61 & 4.37 & 0.00 \\
\hline
\end{tabular}


Based on the Table 5.9, the correlation coefficient between the variables of socio-political factors and the success of implementation of knowledge managementwas 0.611 , indicating that there was a direct relationship between these two variables with a value 0.611 . The adjusted coefficient of determination of socio-political factors was 0.35 . It means that socio-political factors had a $35 \%$ impact on the success of implementation of the knowledge management system.Based on Table 5-10, the significance of this hypothesis was equal to 0.000 . As this value was less than 0.05 , it can be concluded that there was a significant relationship between socio-political factors and the success of implementation of knowledge management system in the statistical sample of the research and this relationship was direct. It means that as socio-political factors had more willingness for the implementation of knowledge management, the odds of success in implementation of a knowledge management system in an organization became higher.

\section{5-1- Friedman test}

Friedman test is used to rank the importance of research variables. This test is equivalent to the parametric method of two-factor analysis of variance in which $\mathrm{k}$ treatment is randomly assigned to $\mathrm{n}$ blocks. A shown in table, from the perspective of the respondents, the most important factors were respectively human resources, cultural factors, structural factors, and socio-political factors, and technology.

Table 5.11. Friedman test to rank factors affecting the implementation of knowledge management

\begin{tabular}{|c|c|c|c|}
\hline & rank & component & Mean rank \\
\hline & 1 & human factors & 3.57 \\
\hline & 2 & cultural factors & 3.38 \\
\hline & 3 & structural factors & 3.37 \\
\hline & 4 & socio-political factors & 2.94 \\
\hline
\end{tabular}

Table 5.12. Friedman test`s significance level

\begin{tabular}{|c|c|}
\hline $\mathrm{n}$ & 34 \\
\hline Chi-square test & 12.68 \\
\hline $\mathrm{df}$ & 4 \\
\hline $\begin{array}{c}\text { Significance level } \\
\text { (sig) }\end{array}$ & 0.01 \\
\hline
\end{tabular}

Chart 5.1 also illustrates the ranking of the factors affecting the implementation of knowledge management.

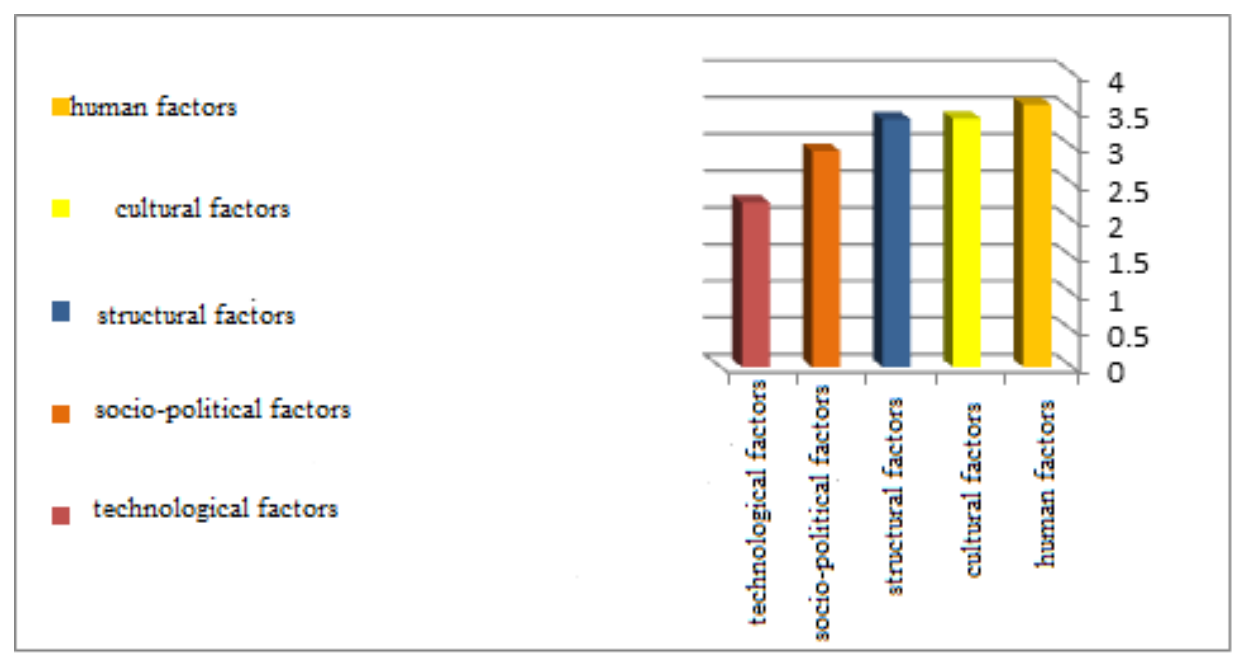

Chart 5.1.Ranking the factors affecting the implementation of knowledge management 


\section{6-Conclusion}

As stated in the previous section, all 5 research hypotheses were confirmed. It should be noted that all five factors had a direct impact on the barriers of implementation of a knowledge management system. By investigating the status of the considered unit in terms of these identified factors, it could be realized that which of these parts needs to be improved. In this research, in the first hypothesis, the relationship between the cultural factors and the implementation of a knowledge management system was examined .In the second hypothesis, the relationship between the structural factors and implementation of a knowledge management system in an industrial organization was examined .In the third hypothesis, the relationship between the technological factors and implementation of a knowledge management system was examined and the role of technological factors in the implementation of a knowledge management system was investigated .In the fourth hypothesis, the role of human factors in the implementation of a knowledge management system was examined .Finally, in the fifth hypothesis, the role of socio-political factors in the implementation of a knowledge management system was examined.

Based on the results, socio-political factors ranked four in terms of the level of impact, but according to the results of the correlation test, it had a direct impact on human factors, indicating that the level of impact of this factor on the management of knowledge was indirect and equal to human factors. According to the research literature, hypotheses were developed and tested through SPSS, version24, software. In short, the results of the research confirmed all of the hypotheses. Chart 5-1 shows the main variables and indicators.Diagram 5-1 shows the research`s final model, derived from tests and hypotheses.

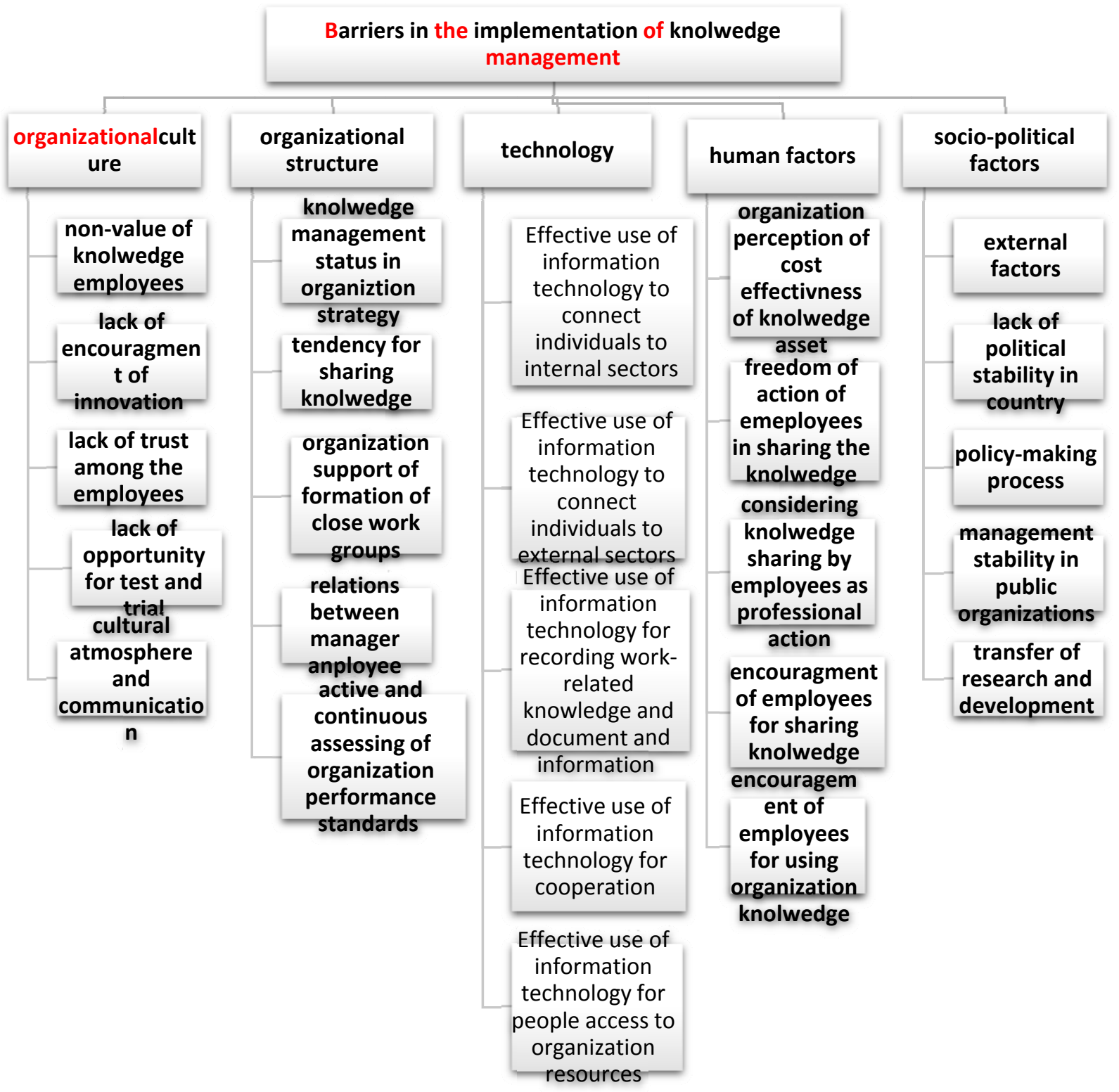

Diagram 5-1- Factors and indicators of barriers regarding the implementation of knowledge management 


\section{7-Recommendations}

As indicators were determined for each of the factors studied in this research, it is recommended that the following steps to be taken into account in order to improve any of the above-mentioned factors in the defense industry of Iran:

To improve and enhance the organizational structure of the defense industry, the following cases are recommended:

-Formation of KM leadership committee to coordinate and integrate knowledge management activities and other key organization processes

-Formation of brainstorming centers and supporting them for solving the organizational problems (these centers provide the conditions for the exchange of thoughts and ideas and sharing of knowledge)

-Linking knowledge management with the core processes of the organization

In order to improve and enhance the socio-political factor in the defense industry, the following cases are recommended:

-Enhancing inter-organizational cooperation for transferring and exchangingthe knowledge through reforming the nature of cooperation contracts from outsourcing to strategic partnerships.

-Developing and presenting appropriate standards for establishing national and international cooperation in order to create a climate of trust and stability in cooperation.

-Presenting product and technology development road maps (with security considerations) to partner networks to express the political stability and create a space for knowledge exchanges in order to reduce the risk of partner network investment and advance technology and reduce the time needed to access the product.

In order to improve and enhance the technology factor in the defense industry, the following cases are recommended:

-Accepting the content generated by the organization by the management team only through information technology

-Supporting the creation of virtual knowledge sharing centers such as forums, chat rooms, blogs and more.

-Designing software such as system engineering and its relationship with project management processes, knowledge management and technology management for instant recording of documents

In order to improve and enhance the human resources factor in the defense industry, the following cases are recommended:

-Developing apprenticeship method to transfer knowledge from expert individuals to novice people

-Encouraging and rewarding the documentation, sharing and using organizational knowledge resources

-Sharing personal and organizational knowledge maps through IT infrastructure

-Facilitating the displacement of designers and researchers and access to knowledge assets

-Valuation of produced knowledge assets and assigning it to its producers to give identify for them.

-In order to transfer the experiences and findings of retiring employees, it is recommended to oblige them to record their events and experiences 3 years before their retirement.

-The use of expert and elite employees who have been retired from industrial organizations of defense ministry as advisors for three years along with young and inexperienced employees to transfer all of their findings and techniques to these employees.

-Considering financial and spiritual incentives for employees who are using the methods of converting tacit knowledge into explicit knowledge

In order to improve and enhance the organizational culture factor in the defense industry, the following cases are recommended:

-Modifying and reforming employee evaluation indicators in appointments and promotions based on the concepts of the knowledge management cycle (such as sharing, documentation, etc.)

-Reviewing the administrative regulations and rules to facilitate the knowledge communications and scientific and technical cooperation between the organization and employees 
-Creating mechanisms for collecting and examining the ideas, facilitating the presence of employees in scientific associations and communities in order to learn and transfer knowledge recording what has been lessoned and sharing them.

-Alignment of security regulations with business dynamics

- Designing the path of growth and maturity in the implementation of knowledge management based on key indicators of success

-Developing protocols for intellectual property rights (for example, modifying the identity of the documents and inserting the name of the developers in them, along with the contribution of each, the emphasis on referral to the organizational documents, etc.).

\section{8-References}

[1] Akhavan, P, and Jafari, M (2005). Failure of knowledge management in organizations. TadbirSceinceTraining Journal 161, 26-28.

[2] Sadeghi, F (2008). Barriers of implementation of knowledge management in organizations, Electrical Engineering Monthly Journal , $143,16-28$.

[3] Domport, T and Prosac, L (2000). knowledge management. (Translated by Hosein Rahman Seresht) Tehran: Samt Publication.

[4] Abdol Shah, M, Abdol Shah, S (2012). Barriers of Implementation of Knowledge Management in Industrial Organizations, International Journal of Engineering and Management.

[5] Kameli, MJ (2008). Knowledge Management and its Barriers of Public Organizations, Karagah Monthly Journal, 25, 2-3

[6] Domport, T and Prosac, L (2000). Knowledge management. (Translated by Hosein Rahman Seresht) Tehran: Sapko Publication, 2000

[7] Davenport, T., \& Grover, V. (2001). Knowledge Management. Journal of Management Information Systems,

[8] NilminiWickramasinghe, \& Dag von Lubitz (2007). Knowledge-based Enterprise: Theories and Fundamentals. Idea Group Publishing

[9] Madhavm. R. and Grover. R. 1998. From Embedded Knowledge to Embodied Knowledge: New Product Development as Knowledge Management. Journal of Marketing, 62(4): 1-12

[10] Wickramasinghe, N. (2005). The Phenomenon of Duality: The Key to Facilitating the Transition form Knowledge Management to Wisdom for Inquiring Organizations. In Courtney et al. (Eds.), Inquiring organizations: Moving form Knowledge Management to Wisdom. Hershey, PA: Idea Group Publishing

[11] Cohen, Wesley \& Leviathan. 1990. Absorptive Capacity: A New Perspective On Learning And Innovation. Administrative Science Quarterly, voI.35: 128-1 52

[12] Nonaka 1. and Takeuc hi. H. 1 995. The Knowledge-Crrating Company: How Japanese Companies Create the Dynamics of Innovation. Oxford University Press.

[13] Wickramasinghe, N., Fadlalla, A., Geisler, E., \& Schaffer, J. (2003). Knowledge Management and Data Mining: Strategic Imperatives for Healthcare. Proceedings of the 3rd Hospital of the Future Conference

[14] Wilcox, L. (1997). Knowledge-based Systems as an Integrating Process. In J. Liebowitz \& L. Wilcox (Eds.), Knowledge Management and its Integrative Elements (pp. 1-30). Boston: CRC Press.

[15] Mills, G. (2001). MARS: The Electronic Medical Record System the Core of the Kaiser Galaxy. International Journal of Healthcare Technology Management, 3(5/6), 406-423.

[16] Drucker, P. (1993). Post-Capitalist Society. New York: Harper Collins. Nonaka, I kujiro. 1994. A Dynamic Theory of Organizational Knowledge Creation. Organization Science, vol. 5, no.1: 14-37

[17] Dr Stewart Hase , Dr Shankar Sankaran, Dr Alan Davies , 2006 , Overcoming barriers of knowledge management : Visiting the dark side of organizations , actKM Online Journal of Knowledge Management ,Volume 3 , Issue 1

[18] Karabag ,Atila , 2010 , Critical barrier and success factors for implementing knowledge management in organizations , CEMS Doctoral Seminar, Preston , 22 th - 25th of June 3- Frank Lindner, Andreas Wald, October 2011, Success factors of knowledge management in temporary organizations , International Journal of Project Management , Volume 29 , Issue 7, Pages 877-888

[19] Lutz Preuss , Jose-Rodrigo Córdoba-Pachon , 2009 , A knowledge management perspective of corporate social responsibility , Corporate Governance, Vol.9 , 517-527

[20] M . du Plessis August 2008, What bars organizations from managing knowledge successfully ? International Journal of Information Management, Volume 28 , Issue 4 , Pages 285-292

[21] M.D. Singh , R. Kant , 2008 , Knowledge management barriers : An interpretive structural modeling approach , International Journal of Management Science ,Vol.3 No.2 , pp 141-150

[22] RynhardtRall , 2008 , Barriers and facilitators to knowledge management in multi-national companies : The case of Nissan , Gordon Institute of Business Science

[23] Tsung-Han Chan \& Tien-Chin Wan , 1 February 2009 , Using the fuzzy multi-criteria decision making approach for measuring the possibility of successful knowledge management, Information Sciences, Volume 179 , Issue 4 , Pages 355-370 9- Valmohammadi. Changiz, June 2010 , Identification and prioritization of critical success factors of knowledge management in Iranian SMEs :An experts'view , African Journal of Business Management Vol. 4(6), pp . 915-924

[24] Wei-Wen Wu , October 2008 , Choosing knowledge management strategies by using a combined ANP and DEMATEL approach , Expert Systems with Applications ,Volume 35, Issue 3, Pages 828-83 